\title{
Superhydrophobic and Omnidirectional Antireflective Surfaces from Nanostructured Ormosil Colloids
}

\author{
Adem Yildirim, ${ }^{\dagger \neq}$ Tural Khudiyev, ${ }^{\dagger, \ddagger}$ Bihter Daglar, ${ }^{\dagger, \ddagger}$ Hulya Budunoglu, ${ }^{\dagger, \ddagger}$ Ali K. Okyay, ${ }^{\dagger, \ddagger, \S}$ \\ and Mehmet Bayindir ${ }^{\dagger,}, \|, *$
}

${ }^{\dagger}$ UNAM-National Nanotechnology Research Center, ${ }^{\dagger}$ Institute of Materials Science and Nanotechnology, ${ }^{\S}$ Department of Electrical and Electronics Engineering, and "Department of Physics, Bilkent University, 06800 Ankara, Turkey

Supporting Information

ABSTRACT: A large-area superhydrophobic and omnidirectional antireflective nanostructured organically modified silica coating has been designed and prepared. The coating mimics the self-cleaning property of superhydrophobic lotus leaves and omnidirectional broad band antireflectivity of moth compound eyes, simultaneously. Water contact and sliding angles of the coating are around $160^{\circ}$ and $10^{\circ}$, respectively. Coating improves the transmittance of the glass substrate around $4 \%$, when coated on a single side of a glass, in visible and near-infrared region at normal incidence angles. At oblique incidence angles (up to $60^{\circ}$ ) improvement in transmission reaches to around $8 \%$. In addition, coatings are mechanically stable against impact of water droplets from considerable heights. We believe that our inexpensive and durable multifunctional coatings are suitable for stepping out of the laboratory to practical outdoor applications.

KEYWORDS: superhydrophobic, self-cleaning, organo-modified silica, antireflection, omnidirectional, functional surfaces

\section{INTRODUCTION}

Several biological organisms have been synthesizing functional nano- and microstructures in order to obtain desired surface property. ${ }^{1,2}$ Well known examples of these functional surfaces include self-cleaning surface of lotus leaves ${ }^{3}$ and antireflection structures on moth compound eyes. ${ }^{4}$ Lotus leaf surface comprises of micro-/nano-hierarchical structures, and the tops of these structures are coated with a thin hydrophobic wax layer. Such a hierarchically rough and low energy surface provides stable superhydrophobicity with high water contact angle, small hysteresis, and easy rolling of water droplets away from the surface. This type of superhydrophobicity can be explained according to the Cassie-Baxter model in which water droplets rest on a surface composed of air trapped in the microgrooves of a rough surface and tops of these microstructures. ${ }^{5,6}$ To obtain such a composite interface between water and the surface, it must be roughened conveniently and coated with low surface free energy materials. ${ }^{7,8}$ An ordered hexagonal array of subwavelength nipples on moth compound eyes, on the other hand, results in antireflection over a broad range of wavelengths by eliminating the destructive interference between air-array and array-surface interfaces. ${ }^{4}$ Inspired from such biological examples, many successful approaches have been developed to prepare functional surfaces with self-cleaning or antireflection property, using lithographic methods, ${ }^{9-13}$ deposition of micro-/nanoparticles, ${ }^{14-17}$ phase separation in polymers, ${ }^{18-20}$ layer by layer deposition methods, ${ }^{21-23}$ and sol-gel methods. ${ }^{24-28}$

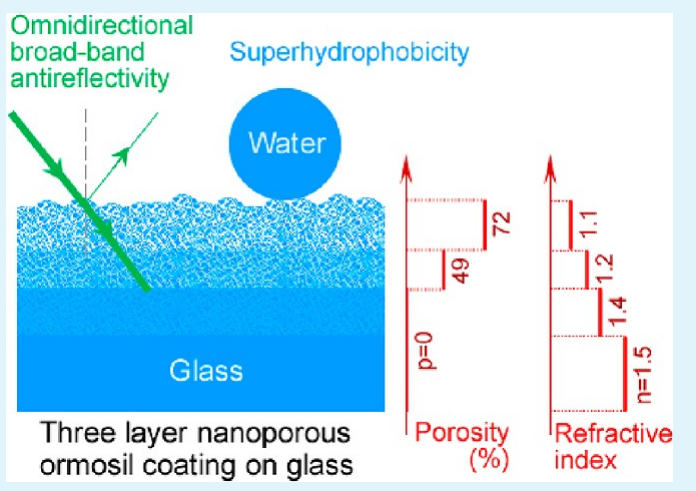

On the other hand, an optically transparent surface (e.g., glass, quartz, and PMMA) that exhibits both self-cleaning and antireflection features would be very beneficial in many applications such as solar cells, LEDs, and optical lenses since such highly transparent and water repellent surfaces can improve the device performance by eliminating the reflection losses and also offer low cost maintenance due to the selfcleaning property. ${ }^{29}$ However, the challenge in preparing such multifunctional surfaces is to balance the high surface roughness requirement of superhydrophobic coatings with the low surface roughness requirement of antireflection coatings. ${ }^{30}$ Therefore, to prepare antireflective and superhydrophobic surfaces, roughness must be optimized; it must be small enough to avoid diffuse reflection from the surface and high enough to provide superhydrophobicity. Although some groups have prepared surfaces combining the superhydrophobicity and high light transmission, ${ }^{31-39}$ there are still several drawbacks that hinder the practical outdoor applications of such multifunctional coatings. First of all, mechanical and thermal durability, which are essential for outdoor applications, are not sufficient or even not investigated for most of the coatings. Also, among such multifunctional coatings, highly water repellent ones generally exhibit antireflection property in a narrow range of wavelengths, or they can even diminish the light transmission of their substrates especially at low

Received: October 23, 2012

Accepted: January 2, 2013

Published: January 2, 2013 
wavelengths $(<500 \mathrm{~nm})$ because of their rough surfaces. On the contrary, the coatings with high antireflectivity generally demonstrate poor water repellency, with low water contact angles and high sliding angles. In addition, most of the multifunctional surface fabrication methods are multistep and require expensive and sophisticated equipments. To our knowledge, all of the reported self-cleaning antireflection surfaces possess at least one of the above-mentioned drawbacks. Therefore, inexpensive and facile large-area fabrication methods are still needed for production of robust self-cleaning antireflection surfaces with good water repellency and broadband (in visible and near-infrared (NIR) region) and omnidirectional (broad range of incidence angles) antireflective property.

In this context, we report the large-area fabrication of selfcleaning antireflection glass surfaces using an inexpensive spin coating method which utilizes nanostructured organically modified silica (ormosil) colloids (Figure 1). The multifunc-

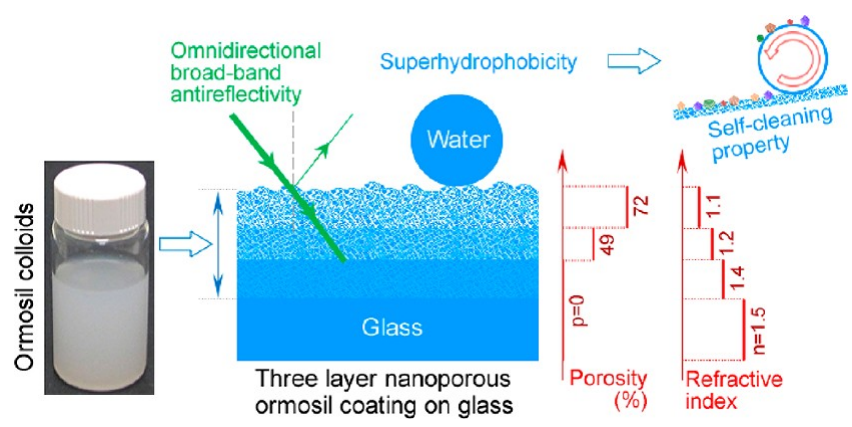

Figure 1. Preparation of multifunctional ormosil coatings. Glass substrates were coated with different ormosil layers possessing gradually decreasing refractive indices and increasing porosity, successively. After heat treatment, the top layer became superhydrophobic with self-cleaning property. Engineered three-layer ormosil coating exhibits broad band and omnidirectional antireflection property.

tional surface consists of three ormosil layers, which have gradually increasing refractive indices from air/coating interface to coating/substrate interface. The multilayered structure provides omnidirectional antireflection property (up to incidence angles of $60^{\circ}$ ) in both visible and near-infrared wavelengths. The diversity in the nanostructure of synthesized ormosil colloids enables adjustment of the surface roughness of the layered structure to obtain superhydrophobicity without causing considerable light scattering. Water droplets easily roll off from its surface at around $10^{\circ}$ tilting indicating good water repellency (contact angle is close to $160^{\circ}$ ). Furthermore, coatings are highly durable against impact of water droplets from considerable heights and acidic/basic environments.

\section{EXPERIMENTAL SECTION}

Materials. Tetraetyl orthosilicate (TEOS), tetramethyl orthosilicate (TMOS), methyltrimethoxysilane (MTMS), oxalic acid, and ammonium hydroxide (25\%) were purchased from Merck (Germany), ethanol and hydrochloric acid $(37 \%)(\mathrm{HCl})$ were purchased from Sigma-Aldrich (U.S.A.), and methanol was purchased from Carlo-Erba (Italy). All chemicals were used as received.

Preparation of Nanoporous Ormosil Coatings. To prepare ormosil coatings first ormosil gels were synthesized by modifying a previously reported method. ${ }^{40}$ In the first step, $x \mathrm{~mL}(x$ is between 0.4 and 1) of MTMS and $1-x \mathrm{~mL}$ of TMOS were added to $9.74 \mathrm{~mL}$ of methanol. Then, $0.5 \mathrm{~mL}$ of $0.01 \mathrm{M}$ aqueous oxalic acid solution was added to the solution dropwise under gentle stirring. The reaction mixture was further stirred for $30 \mathrm{~min}$ and left for complete hydrolysis for $24 \mathrm{~h}$ at room conditions. Condensation was started by dropwise addition of $0.42 \mathrm{~mL}$ of ammonium hydroxide $(25 \%)$ and $0.19 \mathrm{~mL}$ of water mixture under gentle stirring, and the reaction mixture was further stirred for $15 \mathrm{~min}$. Finally, the solution was poured into a polystyrene vial and left for gelation at $25{ }^{\circ} \mathrm{C}$. Gels were formed typically within one day, and they were aged for two days to strengthen the porous structure. After aging, $12 \mathrm{~mL}$ of methanol was added to the gels, and the resulting mixture was sonicated for $45 \mathrm{~s}$ at $20 \mathrm{~W}$ using an ultrasonic liquid homogenizer in order to obtain ormosil colloids. ${ }^{26,41}$ The colloids were spin coated on clean glass surfaces at $2000 \mathrm{rpm}$ and dried at room temperature overnight. To increase the hydrophobicity and integrity of the coatings, they were heated to $450{ }^{\circ} \mathrm{C}$ for $1 \mathrm{~h}$. The colloids and corresponding coatings were named with the number in the abbreviation indicating the TMOS volume fraction in the corresponding colloid, such that TM 7.5 indicates the coating produced using the colloid containing $7.5 \%$ TMOS and 92.5\% MTMS.

Preparation of Nonporous Ormosil Coatings. Nonporous ormosil coatings (NPF) were prepared by modifying the previous methods. ${ }^{42,43}$ In a standard procedure, $4.5 \mathrm{~mL}$ of MTMS (for NPF 1) or $3 \mathrm{~mL}$ of MTMS and $1.5 \mathrm{~mL}$ of TEOS (for NPF 2) were dissolved in $4.5 \mathrm{~mL}$ of ethanol and $0.4 \mathrm{~mL}$ of water, and $10 \mu \mathrm{L}$ of $0.1 \mathrm{M} \mathrm{HCl}$ were added. The reaction mixture was stirred $(250 \mathrm{rpm})$ at $60{ }^{\circ} \mathrm{C}$ for $90 \mathrm{~min}$. Then, $0.8 \mathrm{~mL}$ of $0.1 \mathrm{M} \mathrm{HCl}$ and $0.7 \mathrm{~mL}$ of water were added, and the reaction mixture was further stirred for $15 \mathrm{~min}$ at room temperature. Then, the solution was aged at $50{ }^{\circ} \mathrm{C}$ for $15 \mathrm{~min}$ and diluted with an appropriate amount of ethanol. For example, to prepare $80 \mathrm{~nm}$ thick films, we added $14 \mathrm{~mL}$ of ethanol to the $2 \mathrm{~mL}$ of aged solution. Finally, $200 \mu \mathrm{L}$ portions of diluted sol were coated on clean glass surfaces with spin coating at $2000 \mathrm{rpm}$.

Numerical Simulations. To optimize the omnidirectional broad band antireflection property of the three layer coating, we performed a set of simulations based on the finite difference time domain (FDTD) method. We used plane wave source and Bloch boundary conditions to minimize simulation time. Transmitted light collected by frequencydomain power monitor. To plot transmission as a function of wavelength of light and incidence angle, we used 94 wavelength and 61 angle points in the $340-2200 \mathrm{~nm}$ wavelength and $0-60^{\circ}$ ranges. Optimum refractive indices of bottom layer, middle layer, and top layer were determined as $1.4,1.19$, and 1.1 , respectively, and corresponding thicknesses were determined as top, middle, and bottom layers are $240 \mathrm{~nm}, 140 \mathrm{~nm}$, and $80 \mathrm{~nm}$. Bulk glass assumed to have very large thickness and its refractive index is taken as 1.51 . Detailed information about simulation software was given in ref 44 .

Preparation of Three Layer Coating. We prepared three layer coating by successive spin coating of ormosil solutions at $2000 \mathrm{rpm}$. First, the nonporous ormosil layer (NPF 2) was spin coated as described above and dried at room temperature overnight. To the top of this layer, $140 \mathrm{~nm}$ TM 60 was coated. To give the desired thickness, $4 \mathrm{~mL}$ of TM 60 colloid was diluted using $3 \mathrm{~mL}$ of methanol. This layer was dried at $225{ }^{\circ} \mathrm{C}$ for $1 \mathrm{~h}$. Then, $\sim 240 \mathrm{~nm}$ TM 7.5 layer is coated to the top of the TM 60 layer. To give the desired thickness $2 \mathrm{~mL}$ of TM 7.5 colloid was diluted using $1 \mathrm{~mL}$ of methanol. Finally, coating was cured at $450{ }^{\circ} \mathrm{C}$ for $1 \mathrm{~h}$.

Characterization. The structures of the ormosil colloids were investigated with a transmission electron microscope (TEM, Tecnai G2 F30, FEI) operated at $200 \mathrm{kV}$. The samples were prepared on a holey carbon coated copper grid by placing a drop of the colloidal suspension used for coatings. SEM (E-SEM, Quanta 200F, FEI) was used to observe the structure of coatings at low vacuum condition or at high vacuum condition after coating the samples with $5 \mathrm{~nm}$ of goldpalladium or platinum. AFM (XE-100E, PSIA) was used in noncontact mode to determine the surface morphology and roughness of the coatings. Root mean square (RMS) roughness values of the coatings were calculated from three separate AFM images which were obtained from $10 \times 10 \mu \mathrm{m}^{2}$ regions. An Ellipsometer (V-Vase, J. A. Woollam) was used to measure the refractive index and thickness and to collect specular reflection spectra at oblique incidence angles of the coatings. 
Table 1. Chemical Compositions and Physical Properties of Ormosil Coatings

\begin{tabular}{|c|c|c|c|c|c|c|}
\hline sample & Co-monomer content ${ }^{a}(\%)$ & water contact angle (deg) & contact angle hysteresis (deg) & refractive index $(n)$ & porosity (\%) & roughness $(\mathrm{nm})$ \\
\hline TM0 & 0 & $170.2 \pm 2.4$ & $2.1 \pm 0.8$ & 1.07 & 82 & $124 \pm 3.8$ \\
\hline TM5 & 5 & $159.9 \pm 2.3$ & $7.5 \pm 0.9$ & 1.11 & 72 & $45.9 \pm 4$ \\
\hline TM7.5 & 7.5 & $155.2 \pm 2.3$ & $9.2 \pm 1.9$ & 1.11 & 72 & $28.7 \pm 2$ \\
\hline TM20 & 20 & $134.7 \pm 0.2$ & $22 \pm 0.4$ & 1.17 & 56 & $8.8 \pm 0.8$ \\
\hline TM60 & 60 & $117.1 \pm 2.2$ & $16.7 \pm 0.9$ & 1.2 & 49 & $4.6 \pm 0.3$ \\
\hline NPF1 & 0 & $101.8 \pm 0.8$ & $13.2 \pm 0.8$ & $\mathrm{n} / \mathrm{a}$ & 0 & $10.7 \pm 0.4$ \\
\hline $\mathrm{NPF} 2^{b}$ & 33.3 & $\mathrm{n} / \mathrm{a}$ & $\mathrm{n} / \mathrm{a}$ & 1.4 & 0 & $\mathrm{n} / \mathrm{a}$ \\
\hline
\end{tabular}

${ }^{a}$ Volume percent of total added monomers. ${ }^{b}$ For NPF1 (nonporous film) comonomer is TEOS, for all other coatings comonomer is TMOS.

The Cauchy model $\left(n(\lambda)=A+B / \lambda^{2}+C / \lambda^{4}\right)$ was used to calculate the refractive index and thickness from experimental data since the films are transparent in the experimental range $(400-1000 \mathrm{~nm})$. Also, porosities of the coatings were calculated using the relation between refractive index and porosity. ${ }^{43,45}$ Optical transmission measurements were performed using a UV-vis-NIR spectrophotometer (Cary 5000, Varian). Static, advancing, and receding water contact angles of the coatings were measured using a contact angle meter (OCA 30, Dataphysics). For static contact angle measurements, water droplets of $4 \mu \mathrm{L}$ volume were used with Laplace-Young fitting. For static contact angle measurements at different $\mathrm{pH}$ values, we adjusted the $\mathrm{pH}$ of water using $1 \mathrm{M} \mathrm{NaOH}$ or $\mathrm{HCl}$ solutions. Advancing and receding angles were measured by addition and subtraction of $2 \mu \mathrm{L}$ of water to/ from the droplets of $4 \mu \mathrm{L}$ volume which were placed to the surfaces prior to the measurements. Chemical analysis of surfaces was carried out using X-ray photoelectron spectroscopy (XPS, K-Alpha,Thermo Scientific) and a Fourier transform infrared spectrometer (FTIR, Vertex 70, Bruker). Before XPS measurements, surfaces were cleaned by using argon ion etching in order to avoid experimental errors arising from surface carbon impurities.

\section{RESULTS AND DISCUSSION}

Transparent Superhydrophobic Ormosil Coatings. In this work, first we synthesized a series of ormosil coatings (Table 1) representing different porous structures and surface properties in order to determine proper layers for multilayer coating design. The porous ormosil coatings were prepared using the gels of methyltrimethoxysilane (MTMS) and tetramethylorthosilicate (TMOS) monomers. ${ }^{26,40}$ Ormosil gels were synthesized using a two step acid-base sol-gel reaction. In the first step, monomers were diluted in methanol and hydrolyzed using oxalic acid. In the second step, condensation of hydrolyzed monomers was initiated using ammonia as the base catalyst. Condensation between two monomers resulted in formation of a siloxane bond and a water molecule. From such nucleation sites, the gel network started growth and the gels are formed within several hours to two days, depending on the monomer concentrations. ${ }^{46}$ We observed that TMOS addition increases gelation time. After two days of aging at room conditions, ormosil colloids were prepared by breaking down gel networks using a probe sonicator.

Figure 2 shows the TEM images of ormosil colloids prepared using different monomer compositions. We observed that, as the TMOS ratio increases, the grains of the ormosil network become smaller and also grain size distribution becomes narrower. The grain size distributions and average grain sizes of colloids were calculated based on TEM images (see the Supporting Information, Figure S1). For TM 0, prepared using only MTMS monomer, the average grain size was $26 \pm 9 \mathrm{~nm}$, and it reduced to $5.4 \pm 1.6 \mathrm{~nm}$ when $60 \%$ TMOS was used (TM 60). These results revealed that the grain size distribution of ormosil colloids highly depended on the amount of MTMS
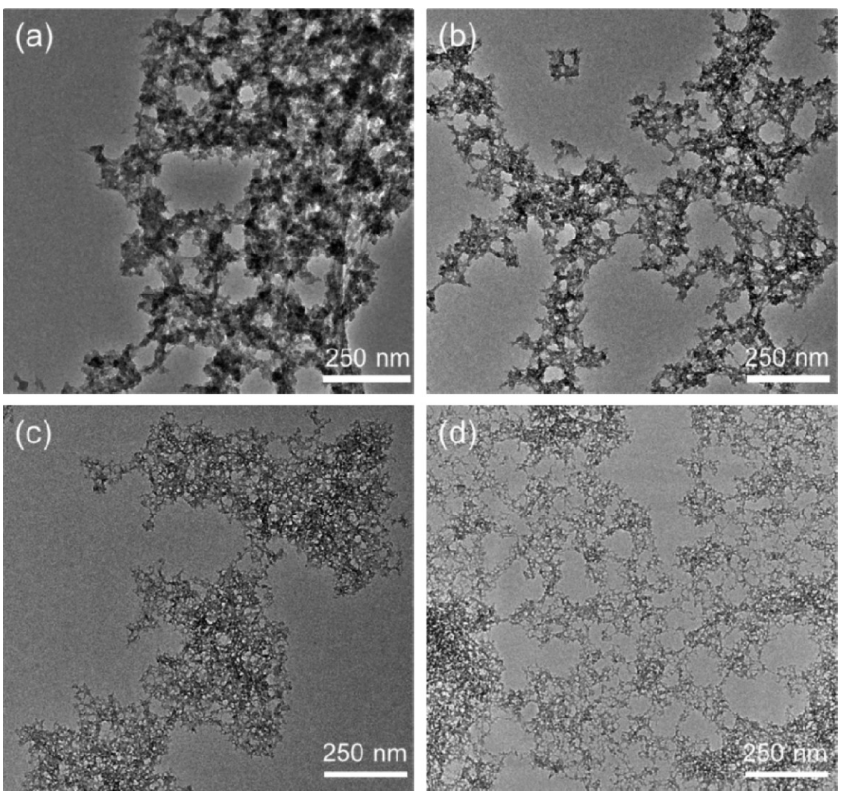

Figure 2. TEM images of the colloids. (a) TM 0, (b) TM 8, (c) TM 25, (d) TM 60. As the MTMS ratio decreases, ormosil colloids composing of smaller grains can be obtained.

monomer used in gel synthesis. ${ }^{28}$ It is well-known that trifunctional MTMS monomer (i.e., it contains three hydrolyzable methoxy and one nonhydrolyzable methyl ligands) induces phase separation in gels due to low solubility of cyclic and cage-like structures formed during polymerization. ${ }^{47,48}$ The phase separation in the gels can be decreased by using some additional tetra-functional monomers such as TMOS and TEOS. ${ }^{28,49}$ Accordingly, ormosil colloids with smaller grains can be obtained from these less phase separated gels.

The ormosil colloids were coated on glass surfaces using spin coating method. During evaporation of solvent, the porous structure of the ormosil colloids first shrunk and then recoiled to its initial porous state due to the hydrophobic surface methyl groups. ${ }^{41}$ Such ormosil coatings are deformable and mechanically and thermally stable and they adhere strongly to plastic (such as polyethersulfone, polyetherimide, and cellulose acetate) and glass substrates thanks to their hybrid nature. ${ }^{26,50}$ To further improve integrity of coatings and their adhesion to glass surfaces, coatings were cured at $450{ }^{\circ} \mathrm{C}$ for $1 \mathrm{~h}$.

The surface morphology of the coatings was characterized using SEM and AFM (Figure 3). TM 0 demonstrated a macroporous and nonuniform coating formation (Figure 3a), and its surface is very rough, $\mathrm{rms}=124 \mathrm{~nm}$ (Figure 3d). By using TMOS comonomer, more uniform and smooth coatings can be obtained (Figure 3b,c). Also, nanoporosity of the coatings can be observed from high magnification SEM images 

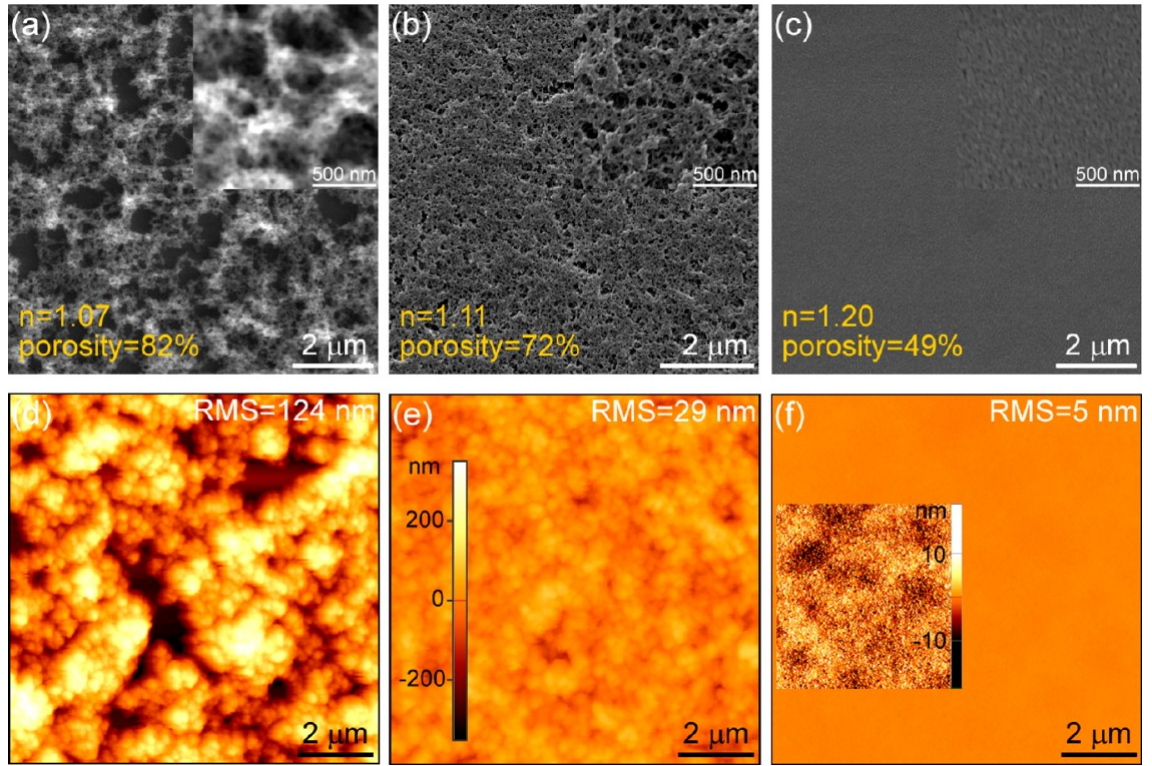

Figure 3. (a-c) SEM images of TM 0, TM 7.5, and TM 60 porous thin films, respectively. Insets shows the higher magnification SEM images of the surfaces. Also, refractive indices and porosities of the coatings were given as inset. (d-f) AFM images of TM 0, TM 7.5, and TM 60, respectively. RMS roughnesses of the coating were calculated from the three individual AFM images and given in the figures. Also, the inset in (f) shows the higher magnification AFM image of the TM 60 surface.

of the surfaces (Figure $3 a-c$ insets). We observed that the pore sizes of the coatings decrease with increasing amount of TMOS. In addition, surface roughness of the coatings was significantly reduced with increasing TMOS ratio, which was 29 $\mathrm{nm}$ for TM 7.5 and $5 \mathrm{~nm}$ for TM 60 (Figure 3e,f and see the Supporting Information, Figure S2). The refractive indices and porosity percentages of all coatings are given in Table 1 . The refractive index and corresponding porosity of TM 0 were found to be 1.07 and $82 \%$, respectively, whereas the refractive index was raised to 1.2 (porosity is $49 \%$ ) for TM 60 . This increase in refractive index and decrease in the porosity is because of the increasing number of surface hydroxyl groups caused by not fully condensed TMOS monomers, which make the pore surface more hydrophilic and facilitate the pore collapse during solvent evaporation. Nevertheless, even at high TMOS ratio (60\%) coatings reveal significant porosity (49\%). The chemical compositions of the surfaces were characterized using XPS (Figure 4). As the TMOS ratio increases, reduction in the height of the carbon peak, which is corresponding to the surface methyl groups, was observed. The carbon ratio of TM 0 was around 16\%; however, it was only $5.7 \%$ for TM 60 .

High water contact angles (WCA) and low contact angle hysteresis $(\mathrm{CAH})$ are essential to obtain highly water repellent surfaces. ${ }^{9}$ Figure 5a shows the WCA and CAH of as prepared and annealed (at $450{ }^{\circ} \mathrm{C}$ ) coatings. We observed high WCA and small $\mathrm{CAH}$ for TM 0 , which were $170.2^{\circ}$ and $2.1^{\circ}$, respectively. In order to demonstrate the effect of roughness on wetting, we prepared a nonporous coating using MTMS monomer (NPF 1). The surface exhibited a much lower surface roughness value $(\mathrm{rms}=10 \mathrm{~nm})$ compared to TM 0 (see the Supporting Information, Figure S3a). Also, WCA and CAH values of NPF 1 were $101.8^{\circ}$ and $13.2^{\circ}$, respectively (see the Supporting Information, Figure S3b). The improved water repellency observed for the porous surface is due to the Cassie-Baxter type wetting of TM 0 thanks to its highly porous, rough, and hydrophobic surface. The WCA of ormosil coatings decreases gradually with increasing TMOS ratio. Also,

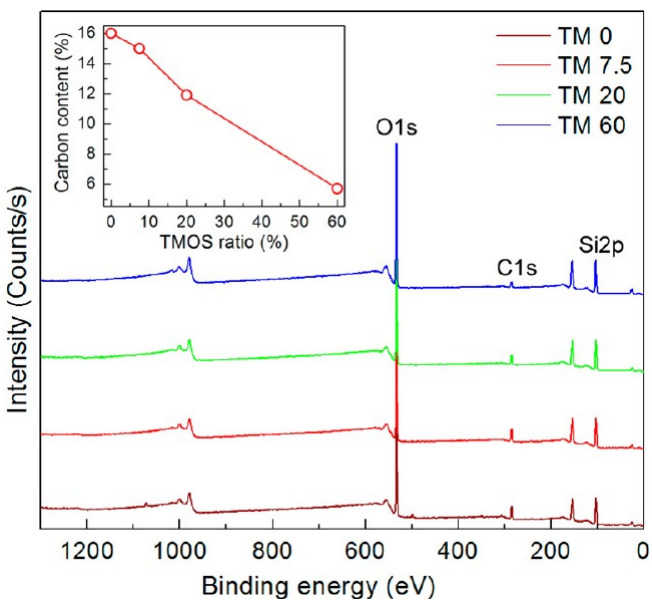

Figure 4. XPS spectra of the coatings. Inset shows the change in the carbon content of the coatings by TMOS addition. It was observed that with increasing amount of TMOS carbon content decreases gradually.

$\mathrm{CAH}$ of the coatings increases after addition of TMOS monomer, with the exception of TM 60 . This reduction in water repellency is due to the decreasing surface roughness and number of hydrophobic methyl groups. Also, Figure 5a revealed that surfaces became more hydrophobic after heat treatment. In order to investigate the reason of the improved hydrophobicity after heat treatment, we used FTIR spectroscopy. FTIR spectra of TM 60 before and after the heat treatment revealed that the peaks related with surface hydroxyl groups were significantly reduced (see the Supporting Information, Figure S4). The dehydroxylation of the surfaces after heat treatment improves the hydrophobicity of coatings. ${ }^{51}$

Figure $5 \mathrm{~b}$ shows the optical transmission measurement of the coatings. We observed that TMOS addition improves the optical transmission of the coatings due to the decreasing surface roughness. When we examine Figure $5 \mathrm{a}, \mathrm{b}$ in detail, we 

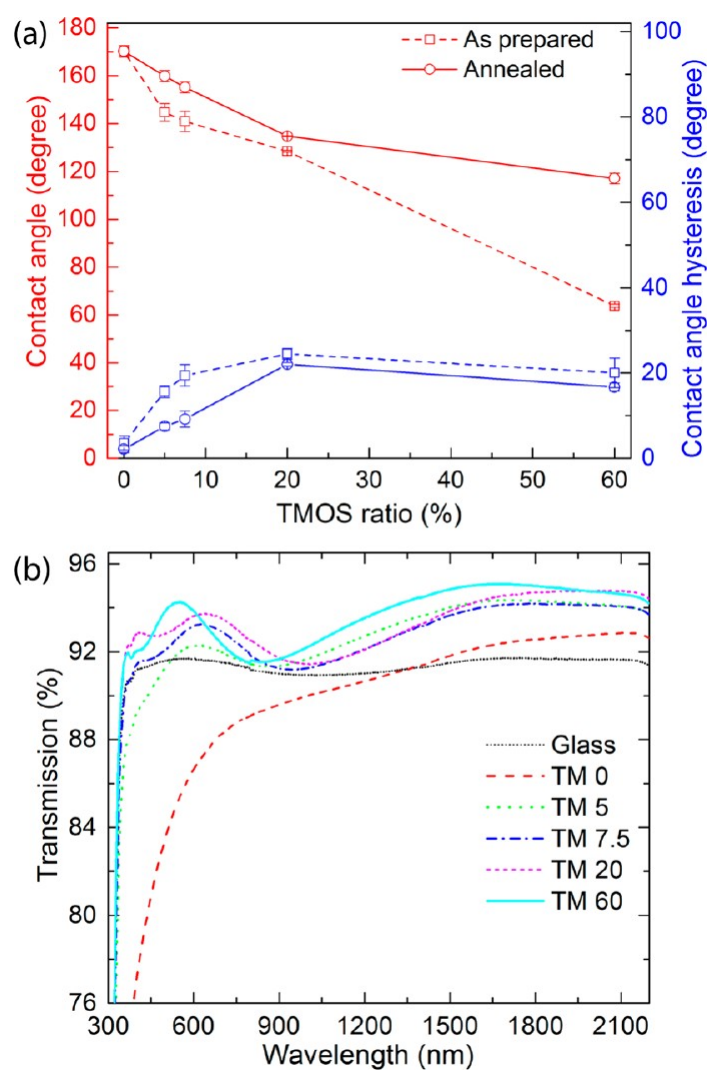

Figure 5. (a) Contact angle and contact angle hysteresis change of the as prepared and annealed coatings, with respect to TMOS comonomer ratio. (b) Transmission spectra of single side coated glass substrates with different ormosil coatings.

observed that TM 7.5 exhibited both optical transparency at all wavelengths between 350 and $2200 \mathrm{~nm}$ and superhydrophobicity with a WCA of $155^{\circ}$ and $\mathrm{CAH}$ of $9^{\circ}$. Other coatings prepared in this work were either superhydrophobic or antireflective, but no other one exhibits both properties simultaneously. The best antireflection property was observed for TM 60 due to its refractive index and is close to the refractive index of an ideal antireflective coating for glass substrate (1.23) according to the Fresnel equation. ${ }^{19}$ Also, it must be noted that transmission maxima of the coatings (Figure $5 b$ ) are in the infrared region because of their high thicknesses between 300 and $500 \mathrm{~nm}$, which were measured by ellipsometrically. The transmission maxima of the coatings can be tuned to visible wavelengths by decreasing the thickness of the coatings simply using more dilute ormosil colloids. ${ }^{27}$

Multifunctional Ormosil Coating. On the basis of above the results and keeping in mind that the gradually increasing refractive index through coating is crucial to achieve broad band antireflection in normal and oblique incidence angles, ${ }^{34}$ we designed a three layer coating through the finite difference time domain (FDTD) simulations. The thicknesses and refractive indices of layers were carefully optimized using FDTD simulations, in order to get best antireflective performance. Accordingly, $240 \mathrm{~nm}$ thick TM 7.5 was selected as the top layer (it exhibits superhydrophobicity with complete transparency and its refractive index is 1.11). The $140 \mathrm{~nm}$ TM 60 was selected as the middle layer (refractive index is 1.2). Finally, 80 $\mathrm{nm}$ thick nonporous ormosil film (NPF 2) having a refractive index of 1.4 was selected as the bottom layer, which was prepared using tetraethyl orthosilicate (TEOS) and MTMS monomers (Figure 1). ${ }^{42,43}$ To realize this multifunctional three layer coating, first the thickness of each layer was adjusted by diluting the ormosil suspensions (see Experimental Section,) then all layers were spin coated sequentially, and the final coating was cured at $450{ }^{\circ} \mathrm{C}$. Figure 6a shows side view SEM image of the three layer coating. Uniform bottom and middle layers and a rough top layer can be easily observed from the image. Also, the top view SEM image demonstrates high porosity of the coating (see the Supporting Information, Figure S5). The average pore size of the three layer coating was calculated using this SEM image. Interestingly, we observed that the surface contains mesopores $(13 \pm 5 \mathrm{~nm})$ and macropores $(87 \pm 30 \mathrm{~nm})$, simultaneously. Figure $6 \mathrm{~b}$ visualized the water droplets on the transparent superhydrophobic surface of three layer coating. Also, it can be clearly observed that three layer ormosil structure coated glass reflects less light than uncoated glass. The transmission spectrum (Figure 6c) of three layer coating shows the broad band antireflection effect. The three layer coating on one side of the glass substrate increases the transmission of light around 4\% between 350 and $2200 \mathrm{~nm}$. For comparison the transmission spectrum of $140 \mathrm{~nm}$ thick TM 60 coated glass is also given in Figure 6c. TM 60 resulted in a transmission increase of $4 \%$ at only a specific wavelength related with its thickness, and except for this point, increase in the transmission was less than $4 \%$. Clearly, three layer coating resulted in a significantly higher increase in transmittance compared to single TM 60 coating. The WCA and CAH of the three layer coating are $159^{\circ} \pm 2^{\circ}$ and $8.7^{\circ} \pm 2.2^{\circ}$, respectively, indicating superhydrophobicity of the surface (Figure 6c, inset). Also, three layer coating demonstrated low water sliding angle which was around $10^{\circ}$ (see the Supporting Information, video S1). In order to demonstrate the self-cleaning property of the three layer coating, dust particles (carbon powder) were spread on the coating surface and then water droplets were dripped to the tilted surface. ${ }^{52} \mathrm{We}$ observed that dust particles were readily removed from the surface by water droplets (see the Supporting Information, video S2), indicating the self-cleaning effect of the coating.

Specular reflection from the uncoated and three layer coated glass substrates were measured using spectroscopic ellipsometry at oblique angles (Figure 6d). Reflection from the uncoated glass substrate between 400 and $1500 \mathrm{~nm}$ was around $4 \%$ and $9 \%$ at incidence angles of $15^{\circ}$ and $60^{\circ}$, respectively. On the other hand, reflection from the three layer coated glass substrate was below $1 \%$ at most of the wavelengths and incidence angles. To further investigate the omnidirectionality of the coating, we performed FDTD simulations (Figure 6e). The $2 \mathrm{D}$ transmission map of the three layer coating demonstrated that the coating provides an increase in transmission for angles up to $60^{\circ}$ in a broad range of wavelengths. Also, simulations for uncoated and $140 \mathrm{~nm}$ TM 60 coated glass substrates are given in the Supporting Information, Figure S6. The simulations demonstrated that three layer coating can more effectively eliminate reflection losses from the glass surface compared to single layer coatings at normal and oblique incidence angles.

Durability of the Three Layer Coating on Glass. Mechanical durability of the three layer coating on a glass surface was examined using water dripping and adhesive tape tests. In the water dripping test, surfaces were treated with $\sim 100 \mu \mathrm{L}$ of water droplets falling from $30 \mathrm{~cm}$ at a rate of one drop per second (Figure 7 inset). ${ }^{32}$ The velocity of the water droplets reaches $\sim 2.5 \mathrm{~m} / \mathrm{s}$ just before they hit the surface. 

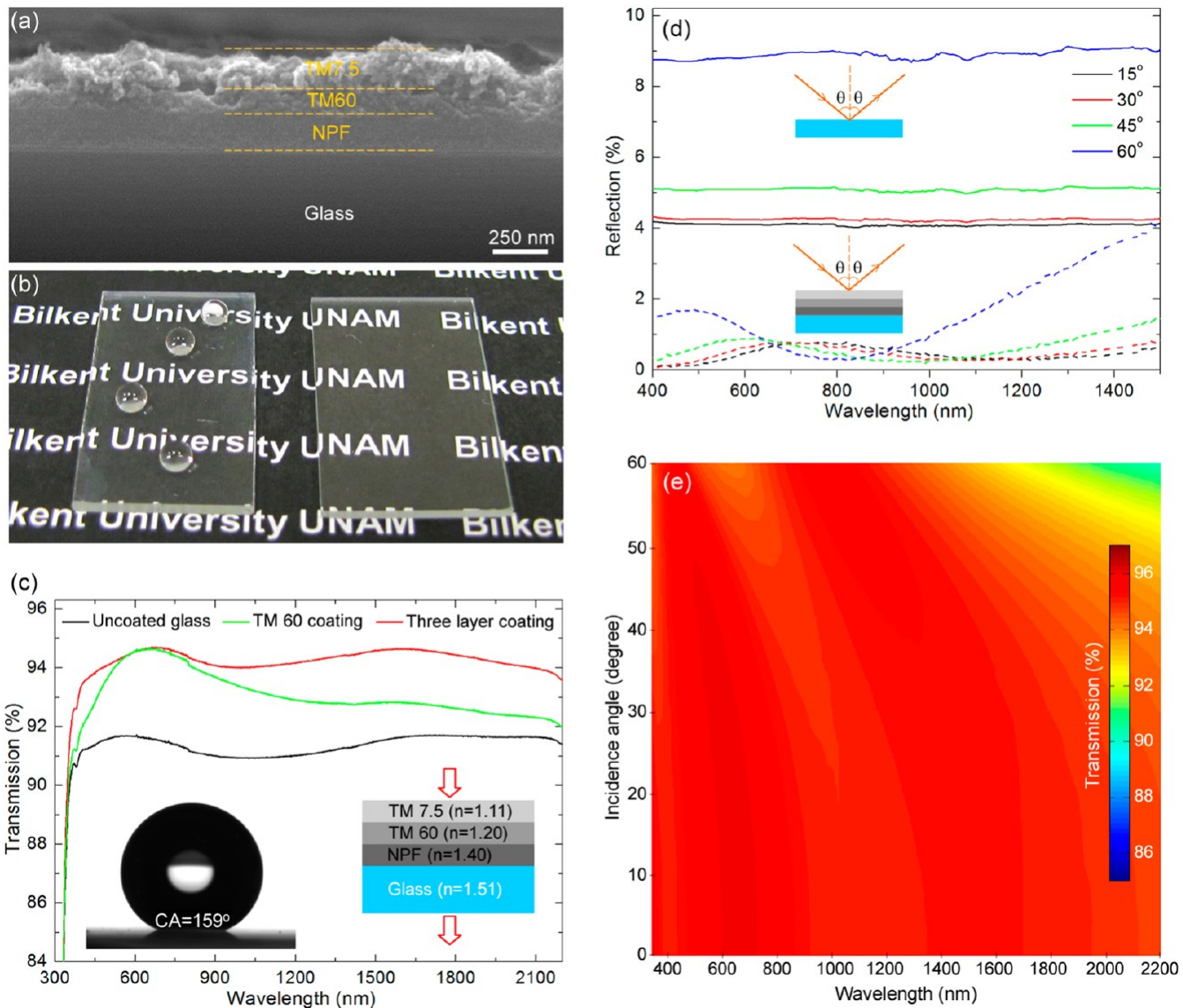

Figure 6. (a) Cross-sectional SEM image of multilayer coating showing the NPF, TM 60, and TM 7.5 layers. (b) Photograph of the multilayer ormosil coated (left) and uncoated glass (right) substrates. (c) Transmission spectra of uncoated, single TM 60 layer coated and three layer ormosil coated glass substrates. Three layer coating significantly improves the light transmission at all wavelengths between 350 and $2200 \mathrm{~nm}$. Insets show (left) the water contact angle of the surface and (right) the refractive indices of each layer. (d) Specular reflections measured by elipsometer from uncoated glass (solid lines) and three layer coated glass (dashed lines) surfaces at oblique angles. (e) FDTD simulations of single-side coated glass substrate transmission depending on wavelength of light and incidence angle showing the omnidirectionality of the coating.

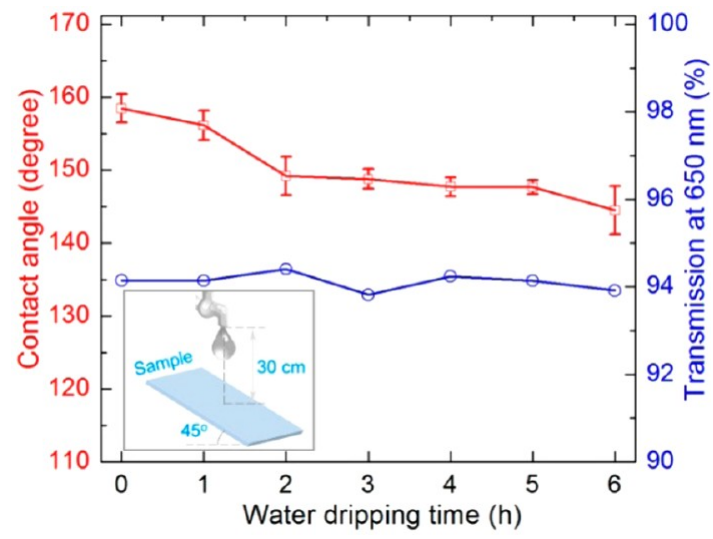

Figure 7. Mechanical durability of optical transparency and water contact angle of the three layer coating as a function of excessive water dripping. Contact angle of the coating reduced to $156^{\circ}$ after $1 \mathrm{~h}$ and to $145^{\circ}$ after $6 \mathrm{~h}$. On the other hand, transmission of the coating remained almost unchanged. Inset shows the schematic illustration of the water dripping test setup.

Figure 7 shows the change in water contact angle and light transmission of the coating during the water dripping test. The transmission of the coating remained almost unaffected after the $6 \mathrm{~h}$ of water dripping ( 21 600 water droplets) indicating the durable antireflection property of the coating. Also, the coating remained superhydrophobic after $1 \mathrm{~h}$ of water dripping (contact angle $\left.\sim 156^{\circ}\right)$, and after $2 \mathrm{~h}(\sim 7200$ water droplets), the contact angle of the surface decreases slightly below the superhydrophobic region. The stability of the superhydrophobic behavior against water dripping of our surface is comparable with a recent mechanically robust superhydrophobic surface ${ }^{53}$ where the coating lost its superhydrophobicity after dripping of $\sim 12000$ water droplets falling from $10 \mathrm{~cm}$ (impact velocity is $1.4 \mathrm{~m} / \mathrm{s}$ ). The surface morphology of the three layer coating after the water dripping test was investigated using SEM and AFM (Figure 8). SEM and AFM images of the water treated surface revealed that coating preserved its integrity after the test. To further investigate the effects of water dripping on surfaces, RMS roughness values of the coating before and after the test were calculated using three separate AFM images, which were obtained from $10 \times 10 \mu \mathrm{m}^{2}$ regions. The RMS roughness of the surface was slightly decreased to $46.3 \mathrm{~nm}$ from $48.1 \mathrm{~nm}$ after the test. This slight decrease in the roughness can be one reason of the observed decrease in the contact angle. Also, we believe that the accumulation of some organic and inorganic contaminants, which can be found in the tap water, was another important reason of this contact angle change. The mechanical durability of the coatings was also tested using an adhesive tape test, where the surface was pressed with adhesive tapes applying approximately $10 \mathrm{kPa}$ and then detached. ${ }^{17}$ After 

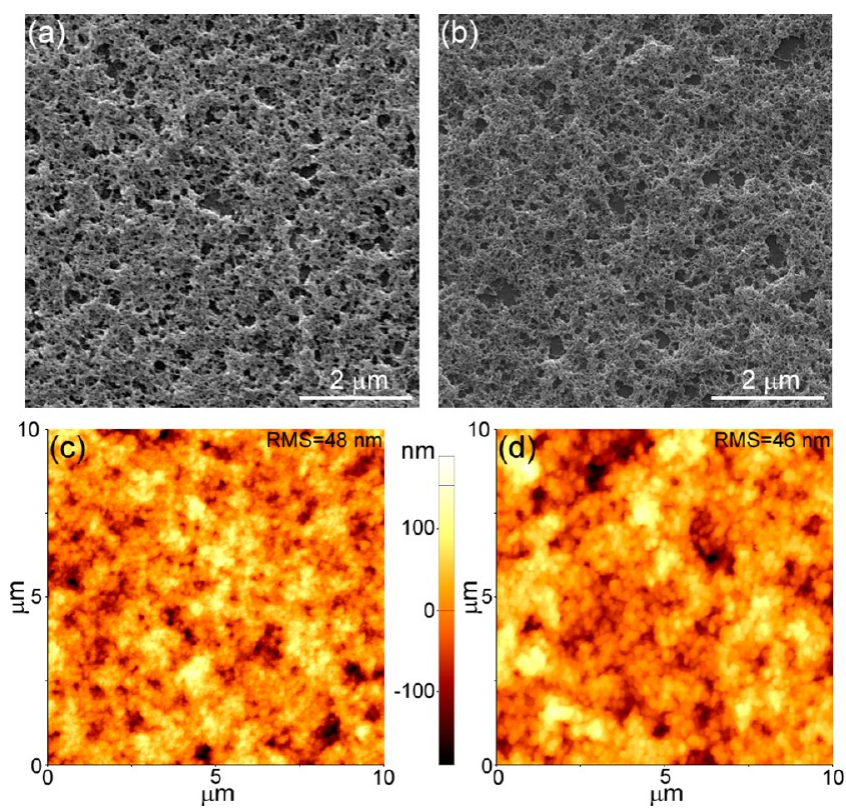

Figure 8. SEM images of the three layer coating before (a) and after (b) and AFM images before (c) and after (d) $6 \mathrm{~h}$ of water dripping test demonstrating that coating remained almost intact after the test.

detaching of the tape, some of the adhesive material of the tape remained on the surface, which disrupted the surface properties. Therefore, it was impossible to obtain reliable contact angle measurement after the test. On the other hand, the adhesive tape test proved the strong adhesion of the coating to the glass substrate, because the remaining adhesive material on the surface indicates that adhesion between the coating and the substrate is stronger than adhesion between the adhesive layer and the tape substrate. Furthermore, it was observed that exposure to a sun ray of TM 0 for three months did not affect the wetting properties of the coating, indicating the outdoor stability of these ormosil coatings. Lastly, we investigated the chemical stability of superhydrophobicity of three layer coating at different $\mathrm{pH}$ values. Figure 9 shows that the contact angle of the three layer coating was stable over a broad $\mathrm{pH}$ range $(\mathrm{pH}$ $1-13$ ) which demonstrated that three layer coating can resist to highly acidic and basic conditions.

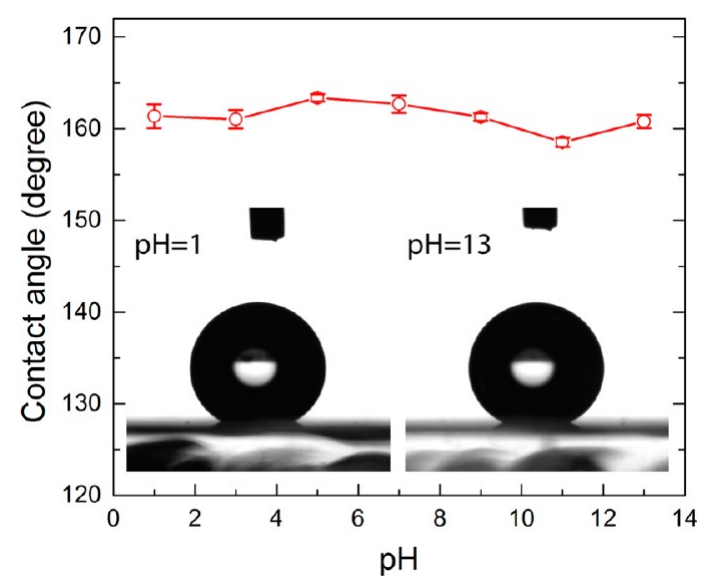

Figure 9. Static contact angle change of the three layer coating on the glass substrate with $\mathrm{pH}$. The three layer coating exhibits good durability over a wide $\mathrm{pH}$ range.

\section{CONCLUSIONS}

We reported a facile method for large-area fabrication of antireflection and self-cleaning coatings on glass using nanostructured ormosil colloids. The coatings demonstrate omnidirectional antireflection in a broad range of wavelengths, covering the whole solar spectrum, and high water contact and low sliding angles. The self-cleaning property of the coating offers low cost maintenance against dirt accumulation on surfaces for outdoor optical and photovoltaic devices over the course of time. Furthermore, the coatings remained almost intact after excessive water dripping and adhesive tape tests. Also, superhydrophobicity of the coatings was stable in acidic and basic environments. In conclusion, these durable large-area multifunctional coatings hold great potential for widespread use in outdoor applications by offering efficiency improvement and low cost maintenance of devices.

\section{ASSOCIATED CONTENT}

\section{S Supporting Information}

(1) A PDF containing figures showing the grain size distributions of ormosil colloids, rms roughness values of coatings, AFM image and contact angle measurement of NPF 1, FTIR spectra of as-prepared and cured TM 60, high magnification SEM image of three layer coating, and additional FDTD simulations. (2) A video showing water repellency of the three layer coating. (3) A video showing self-cleaning property of the three layer coating. This material is available free of charge via the Internet at http://pubs.acs.org.

\section{AUTHOR INFORMATION}

\section{Corresponding Author}

*Corresponding Author E-mail: bayindir@nano.org.tr. Tel: +90312 2903500. Fax: +903122664365.

\section{Notes}

The authors declare no competing financial interest.

\section{ACKNOWLEDGMENTS}

We thank Mecit Yaman and Erol Özgür for fruitful discussions. This work was supported by the TUBITAK Grants 110M412 and 111T696. M.B. acknowledges partial support from the Turkish Academy of Sciences (TUBA).

\section{REFERENCES}

(1) Vukusic, P.; Sambles, J. R. Nature 2003, 424, 852-855.

(2) Xia, F.; Jiang, L. Adv. Mater. 2008, 20, 2842-2858.

(3) Barthlott, W.; Neinhuis, C. Planta 1997, 202, 1-8.

(4) Wilson, S. J.; Hutley, M. C. Opt. Acta 1982, 29, 993-1009.

(5) Cassie, A. B. D.; Baxter, S. Trans. Faraday Soc. 1944, 40, 546551.

(6) de Gennes., P. G. Rev. Mod. Phys. 1985, 57, 827-863.

(7) Li, X. M.; Reinhoudt, D.; Crego-Calama, M. Chem. Soc. Rev. 2007, 36, 1350-1368.

(8) Sun, T. L.; Feng, L.; Gao, X. F.; Jiang, L. Acc. Chem. Res. 2005, 38, 644-652.

(9) Oner, D.; McCarthy, T. J. Langmuir 2000, 16, 7777-7782.

(10) Shirtcliffe, N. J.; McHale, G.; Newton, M. I.; Chabrol, G.; Perry, C. C. Adv. Mater. 2004, 16, 1929-1932.

(11) Raut, H. K.; Ganesh, V. A.; Nair, A. S.; Ramakrishna, S. Energy Environ. Sci. 2011, 4, 3779-3804.

(12) Chuang, S. Y.; Chen, H. L.; Shieh, J.; Lin, C. H.; Cheng, C. C.; Liu, H. W.; Yu, C. C. Nanoscale 2010, 2, 799-805.

(13) Deniz, H.; Khudiyev, T.; Buyukserin, F.; Bayindir, M. Appl. Phys. Lett. 2011, 99, 183107. 
(14) Wang, H. X.; Fang, J.; Cheng, T.; Ding, J.; Qu, L. T.; Dai, L. M.; Wang, X. G.; Lin, T. Chem. Commun. 2008, 877-879.

(15) Fang, J.; Wang, H.; Xue, Y.; Wang, X.; Lin, T. ACS Appl. Mater. Interfaces 2010, 2, 1449-1455.

(16) Lee, D.; Rubner, M. F.; Cohen, R. E. Nano Lett. 2006, 6, 23052312.

(17) Deng, X.; Mammen, L.; Zhao, Y.; Lellig, P.; Müllen, K.; Li, C.; Butt, H. J.; Vollmer, D. Adv. Mater. 2011, 23, 2962-2965.

(18) Erbil, H. Y.; Demirel, A. L.; Avci, Y.; Mert, O. Science 2003, 299, $1377-1380$

(19) Walheim, S.; Schaffer, E.; Mlynek, J.; Steiner, U. Science 1999, 283, 520-522.

(20) Kuo, C. Y.; Chen, Y. Y.; Lu, S. Y. ACS Appl. Mater. Interfaces 2009, 1, 72-75.

(21) Ji, J.; Fu, J. H.; Shen, J. C. Adv. Mater. 2006, 18, 1441-1444.

(22) Zhai, L.; Cebeci, F. C.; Cohen, R. E.; Rubner, M. F. Nano Lett. 2004, 4, 1349-1353.

(23) Shimomura, H.; Gemici, Z.; Cohen, R. E.; Rubner, M. F. ACS Appl. Mater. Interfaces 2010, 2, 813-820.

(24) Xu, Q. F.; Wang, J. N.; Sanderson, K. D. ACS Nano 2010, 4, 2201-2209.

(25) Nakajima, A.; Fujishima, A.; Hashimoto, K.; Watanabe, T. Adv. Mater. 1999, 11, 1365-1368.

(26) Budunoglu, H.; Yildirim, A.; Guler, M. O.; Bayindir, M. ACS Appl. Mater. Interfaces 2011, 3, 539-545.

(27) Yildirim, A.; Budunoglu, H.; Yaman, M.; Guler, M. O.; Bayindir, M. J. Mater. Chem. 2011, 21, 14830-14837.

(28) Budunoglu, H.; Yildirim, A.; Bayindir, M. J. Mater. Chem. 2012, 22, 9671-9677.

(29) The Economist. http://www.economist.com/node/21553480, April 28, 2012.

(30) Cho, K. L.; Liaw, I. I.; Wu, A. H. F.; Lamb, R. N. J. Phys. Chem. C 2010, 114, 11228-11233.

(31) Min, W. L.; Jiang, B.; Jiang, B. Adv. Mater. 2008, 20, 39143918.

(32) Li, Y.; Liu, F.; Sun, J. Q. Chem. Commun. 2009, 2730-2732.

(33) Li, Y.; Zhang, J.; Zhu, S.; Dong, H.; Jia, F.; Wang, Z.; Tang, Y.; Zhang, L.; Zhang, S.; Yang, B. Langmuir 2010, 26, 9842-9847.

(34) Camargo, K. C.; Michels, A. F.; Rodembusch, F. S.; Horowitz, F. Chem. Commun. 2012, 4992-4994.

(35) Xiong, J.; Das, S. N.; Kar, J. P.; Choi, J. H.; Myoung, J. M. J. Mater. Chem. 2010, 20, 10246-10252.

(36) Manca, M.; Cannavale, A.; De Marco, L.; Arico, A.; Cingolani, R.; Gigli, G. Langmuir 2009, 25, 6357-6362.

(37) Li, X.; Du, X.; He, J. Langmuir 2010, 26, 13528-13534.

(38) Ji, S.; Park, J.; Lim, H. Nanoscale 2012, 4, 4603-4610.

(39) Park, K. C.; Choi, H. J.; Chang, C. H.; Cohen, R. E.; McKinley, G. H.; Barbastathis, G. ACS Nano 2012, 6, 3789-3799.

(40) Bhagat, S. D.; Oh, C. S.; Kim, Y. H.; Ahn, Y. S.; Yeo, J. G. Microporous Mesoporous Mater. 2007, 100, 350-355.

(41) Prakash, S. S.; Brinker, C. J.; Hurd, A. J.; Rao, S. M. Nature 1995, 374, 439-443.

(42) Tao, S. Y.; Li, G. T.; Zhu, H. S. J. Mater. Chem. 2006, 16, 45214528.

(43) Yildirim, A.; Budunoglu, H.; Deniz, H.; Guler, M. O.; Bayindir, M. ACS Appl. Mater. Interfaces 2010, 2, 2892-2897.

(44) http://docs.lumerical.com/en/fdtd/knowledge_base.html (accessed Dec. 27, 2012).

(45) Kim, G. S.; Hyun, S. H. Thin Solid Films 2004, 460, 190-200.

(46) Pierre, A. C.; Pajonk, G. M. Chem. Rev. 2002, 102, 4243-4265.

(47) Kanamori, K.; Aizawa, M.; Nakanishi, K.; Hanada, T. Adv. Mater. 2007, 19, 1589-1593.

(48) Dong, H.; Reidy, R. F.; Brennan, J. D. Chem. Mater. 2005, 17, 6012-6017.

(49) Martin, L.; Osso, J. O.; Ricart, S.; Roig, A.; Garcia, O.; Sastre, R. J. Mater. Chem. 2008, 18, 207-213.

(50) Lim, H. S.; Baek, J. H.; Park, K.; Shin, H. S.; Kim, J.; Cho, J. H. Adv. Mater. 2010, 22, 2138-2141.

(51) Zhuravlev, L. T. Langmuir 1987, 3, 316-318.
(52) Park, Y. B.; Im , H.; Im, M.; Choi, Y. K. J. Mater. Chem. 2011, 21, 633-636.

(53) Deng, X.; Mammen, L.; Butt, H. J.; Vollmer, D. Science 2012, $335,67-70$. 


\section{Supporting Information}

\section{Superhydrophobic and Omnidirectional Antireflective Surfaces from Nanostructured Ormosil Colloids}

Adem Yildirim, ${ }^{1,2}$ Tural Khudiyev, ${ }^{1,2}$ Bihter Daglar, ${ }^{1,2}$ Hulya Budunoglu, ${ }^{1,2}$ Ali K. Okyay, ${ }^{1,2,3}$ and Mehmet Bayindir ${ }^{1,2,4^{*}}$

${ }^{1}$ UNAM-National Nanotechnology Research Center, Bilkent University, 06800 Ankara, Turkey

${ }^{2}$ Institute of Materials Science and Nanotechnology, Bilkent University, 06800 Ankara, Turkey

${ }^{3}$ Department of Electrical and Electronics Engineering, Bilkent University, 06800 Ankara, Turkey

${ }^{4}$ Department of Physics, Bilkent University, 06800 Ankara, Turkey

*Corresponding Author: E-mail: bayindir@nano.org.tr 

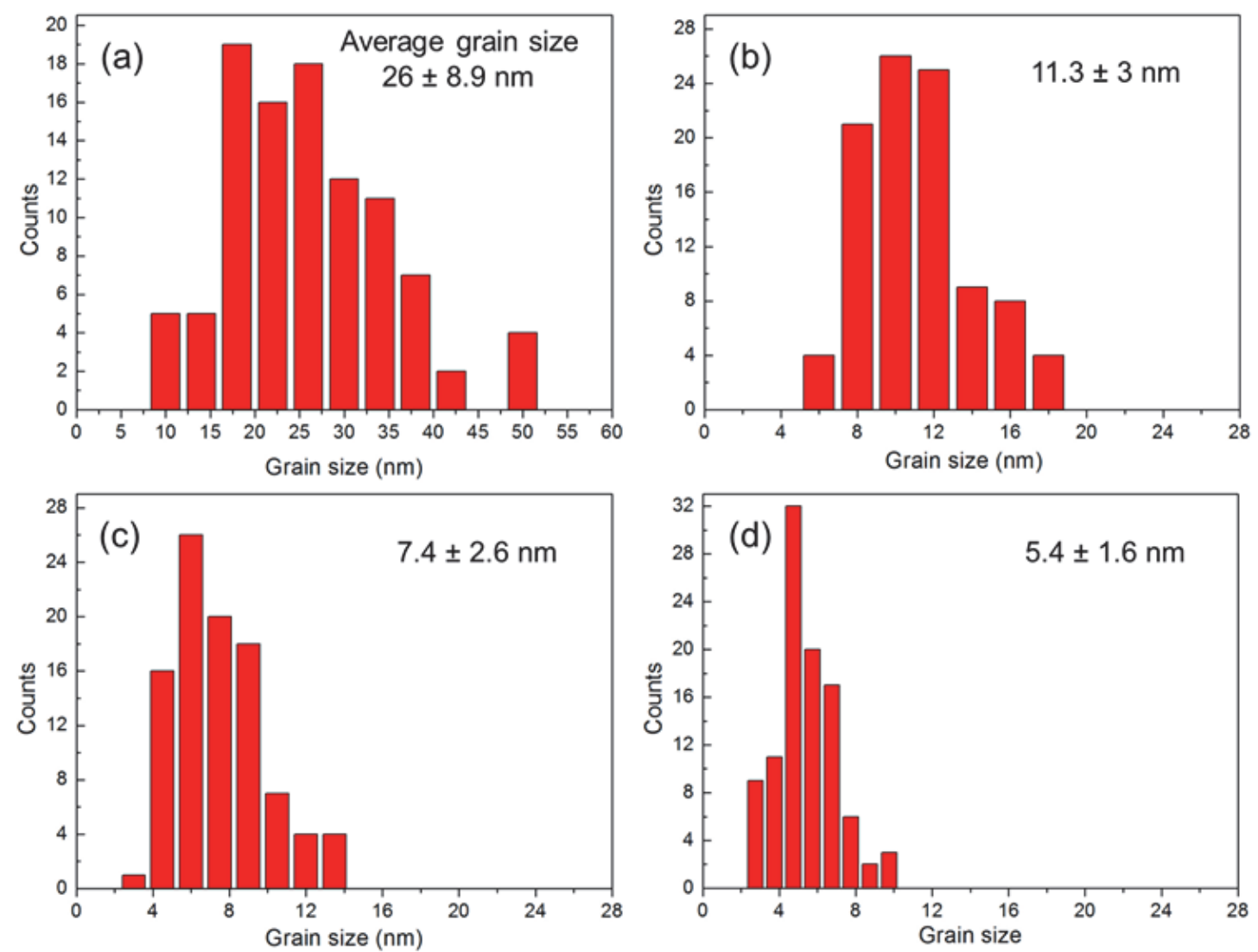

Figure S1. Grain size distribution of the colloids. (a) TM 0, (b) TM 8, (c) TM 25, (d) TM 60. Increasing ratio of TMOS is resulting in a decrease in the average grain size of the colloids. 


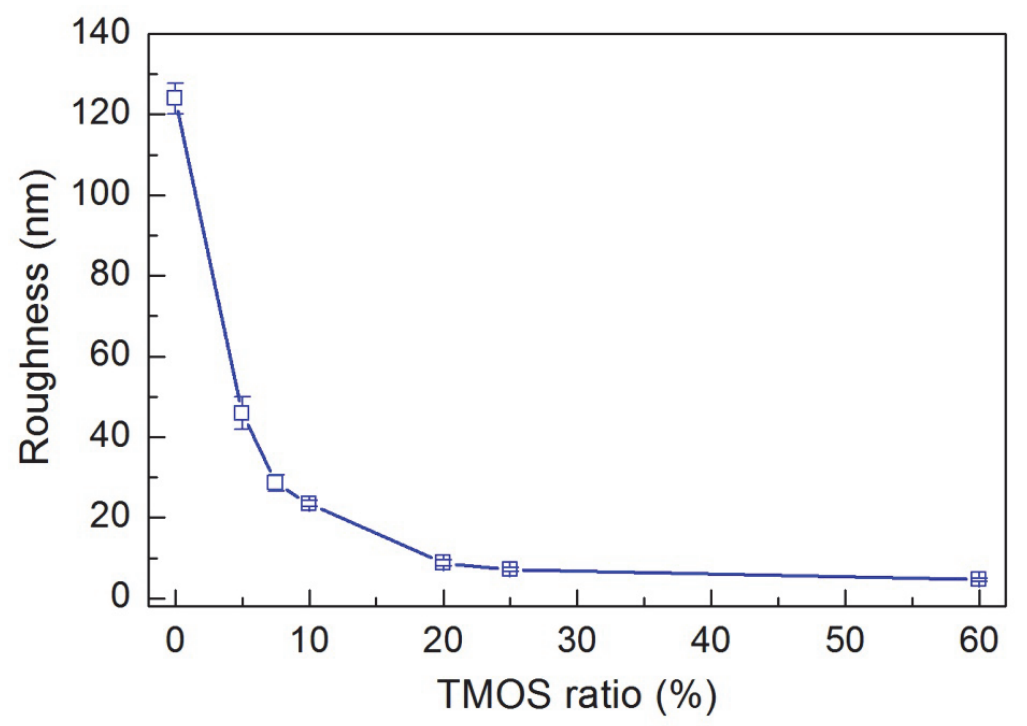

Figure S2. RMS roughness values of the coatings calculated based on three $10 \times 10 \mu \mathrm{m}^{2}$ AFM images. As the TMOS ratio increases the surface roughness dramatically decreases.
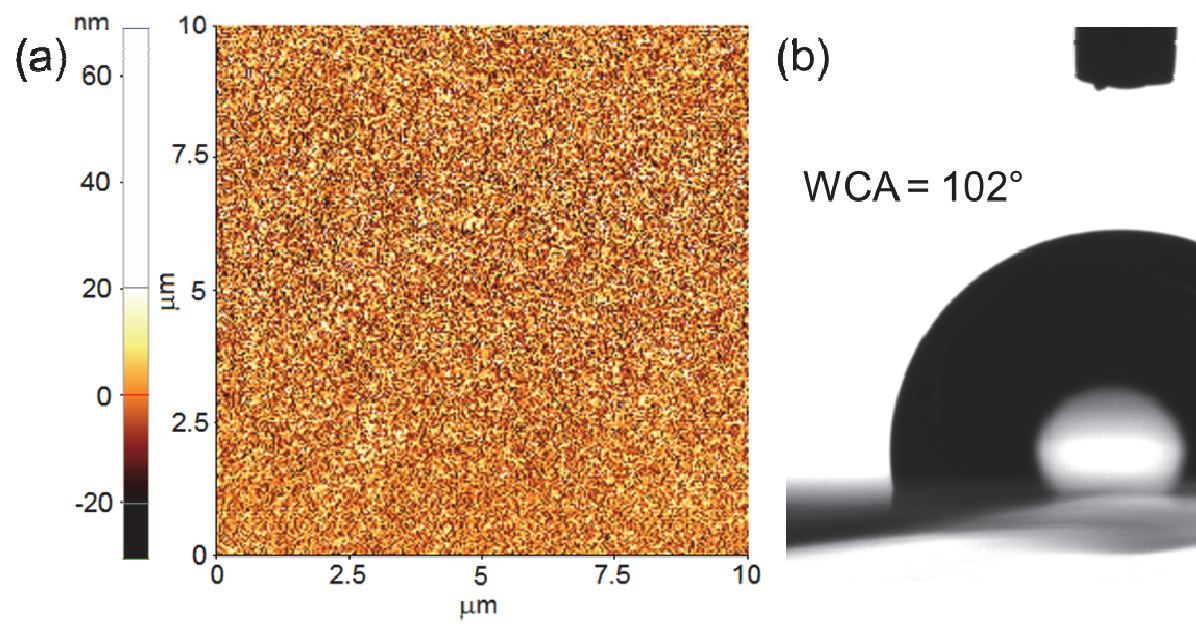

$$
\mathrm{WCA}=102^{\circ}
$$

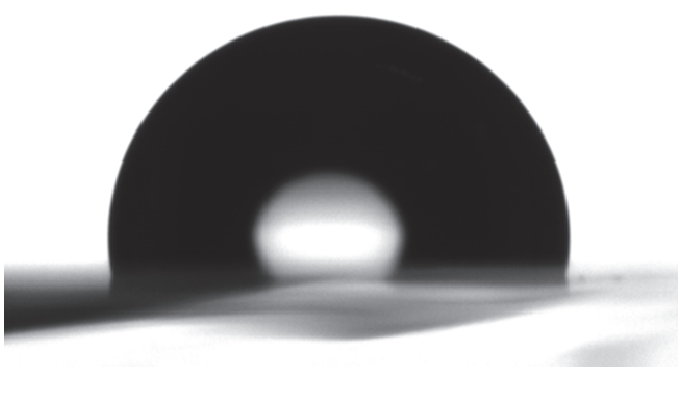

Figure S3. (a) AFM image of the NPF 1 surface. (b) Static water contact angle of the surface. 


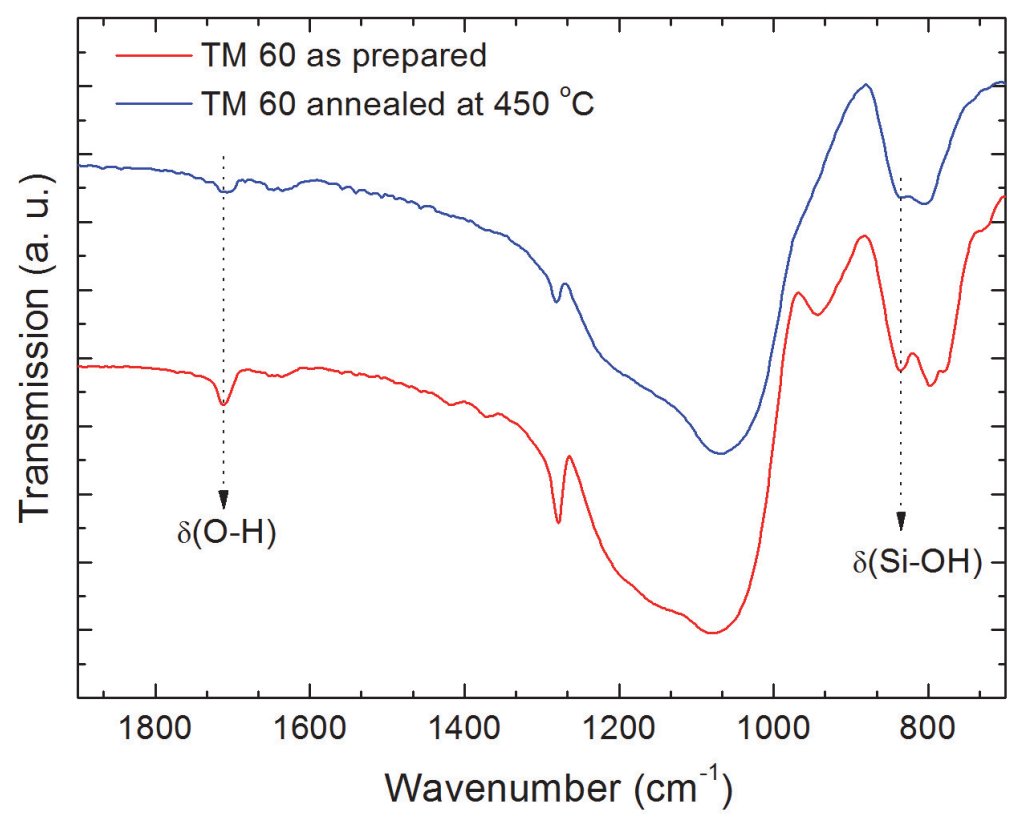

Figure S4. FTIR spectra of TM 60 before and after the heat treatment at $450{ }^{\circ} \mathrm{C}$.

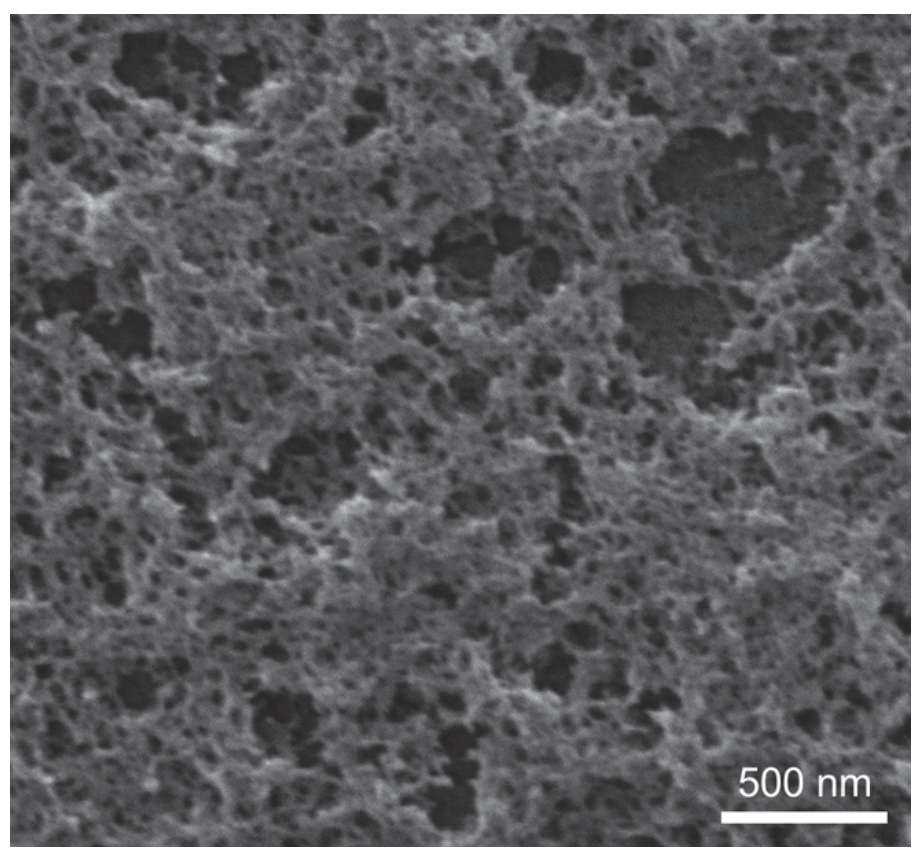

Figure S5. High magnification SEM image of the three layer coating showing the highly porous structure. 


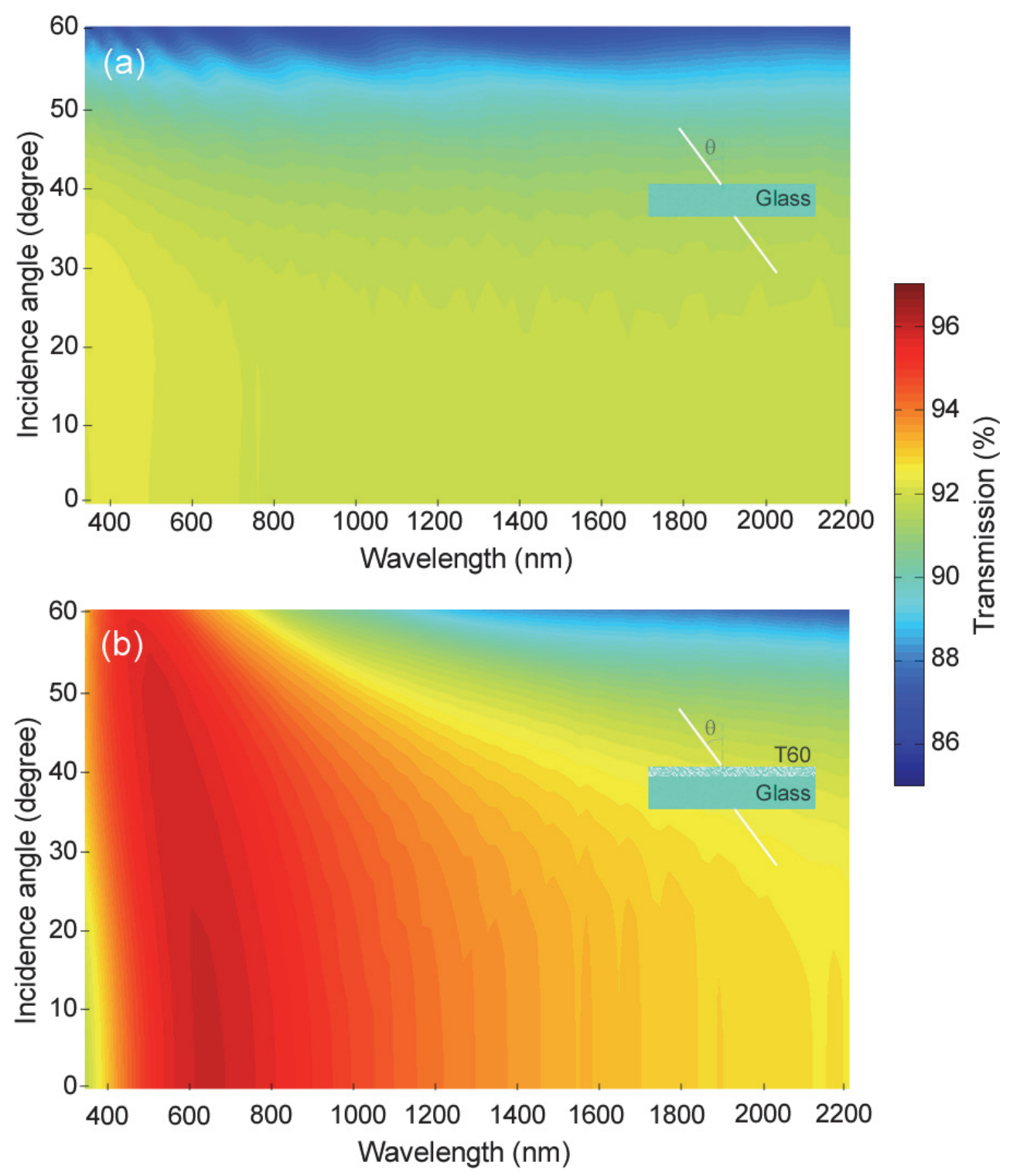

Figure S6. Transmission characteristics obtained from FDTD simulations for (a) bare glass and (b) single side TM 60 coated glass substrates. 